\title{
Excavation damaged zone modelling including hydraulic permeability evolution in unsaturated argilaceous rock
}

\author{
B. Pardoen*, S. Levasseur \& F. Collin \\ ArGEnCo Department, University of Liège, Liège, Belgium \\ ${ }^{*}$ FRIA, F.R.S.-FNRS scholarship holder
}

\begin{abstract}
The drilling of galleries induces damage propagation in the surrounding medium and creates the Excavation Damaged Zone (EDZ) in which the material properties are modified. The prediction of the fracture structure and flow properties evolution within this zone are major issues especially in the context of underground nuclear waste storage. Since experimental results indicate that shear strain localisation appears prior to fractures, we model the EDZ with strain localisation in shear band mode using the coupled local second gradient model. The evolution of the intrinsic hydraulic permeability inside the fractures is taken into consideration as well as the influence of gallery ventilation on the rock desaturation. The numerical results provide information about the damaged zone extension, structure and behaviour with good correspondence to in situ measurements and observations.
\end{abstract}

\section{INTRODUCTION}

In the context of radioactive waste management, the currently envisaged solution is an underground repository in geological media providing good confining properties such as low permeability. The underground structures are composed of galleries whose drillings induce fractures propagation thus an Excavation Damaged Zone (EDZ) is created in the vicinity of the galleries. Within this zone, modifications of the material properties, such as a water permeability increase (Bossart et al. 2002), are observed. Considering the long-term safety function of the host rock formation, the prediction and understanding of the fracturing structure of the damaged zone and the influence of the properties modification are crucial. A particular attention has also to be paid to rock-atmosphere interactions due to the air ventilation performed in the galleries.

Experimental evidences indicate that the damage induced by drilling develops as cracks and that strain localisation in shear band mode appears prior to these cracks (section 2.1). Consequently, we represent numerically the excavation damaged zone with shear strain localisation. A regularisation method is necessary to properly model the strain localisation (Collin et al. 2009) and the coupled local second gradient model has been chosen among different methods. The modelling is performed with the non-linear finite element code Lagamine developed at the University of Liège. Among the different geological media suitable for deep repository, the Callovo-Oxfordian claystone, which surrounds the underground research laboratory (URL) of the French national radioactive waste management agency (Andra), is studied.

In the following work, we firstly focus on the excavation damaged zone definition including evidences of the mechanical fracturing and permeability modification (section 2). Then, the coupled local second gradient model is detailed under unsaturated condition with hydraulic permeability evolution (sections 3 and 4). Finally, we numerically model the development of the EDZ during a gallery excavation. The fractures in the damaged zone are represented by shear strain localisation in bands mode. The variation of the intrinsic hydraulic permeability in the EDZ is taken into account in the modelling. We also apply a ventilation inside the gallery and analyse the desaturation of the rock.

\section{EXCAVATION DAMAGED ZONE}

\subsection{Mechanical fracturing}

Fracturing and damage in geomaterials are due to stress redistribution and propagation of micro-cracks. At small scale, plenty experimental works performed on geomaterials have been devoted to strain localisation. The obtained results permit to conclude that strain localisation in shear band mode is commonly observed and leads to the rupture of many geomaterials (Desrues 2005). 

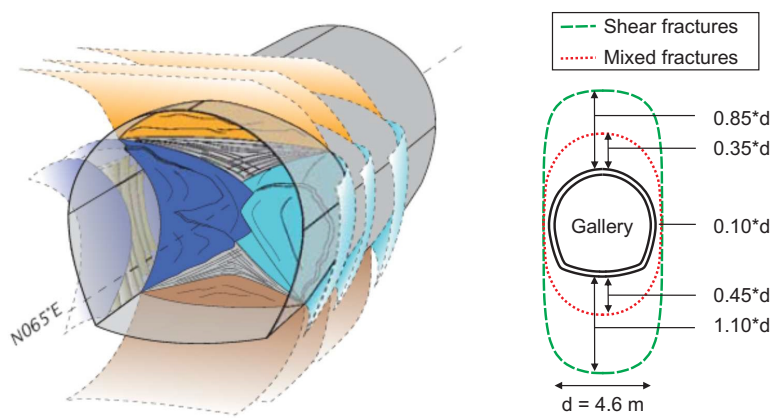

Figure 1: Schematic representation of the fractures (left) and of their extension (right) around a gallery of the Andra URL (from Armand et al. (2013) and Cruchaudet et al. (2010)).

At large scale, the excavation process induces damage propagation in the surrounding medium. Different failure mechanisms can occur and an EDZ, possibly composed of macro-scale fracturing, is created. Focusing on the Callovo-Oxfordian claystone, in situ measurements and observations of fractures have been performed by the Andra to characterise the EDZ. A brief summary concerning one experimental gallery (GED) from Armand et al. (2013), is detailed in the figure 1. It illustrates a schematic representation of the chevron fractures and the extension of the fractured zone composed of mixed fractures, in shear and tensile mode, close to the gallery and shear fractures deeper in the rock.

\subsection{Hydraulic permeability modification}

Tsang et al. (2005) define the EDZ as a zone dominated by geochemical and hydromechanical property changes which induce important modifications in flow and transport properties. Among the property changes, the water permeability can increases of several orders of magnitude in the fractures appearing in the vicinity of the gallery (figure 2 from Bossart et al. (2002) and Cruchaudet et al. (2010)). The Andra performed measurements of the water permeability around the galleries of its URL, two zones are defined : one where the permeability is highly disturbed, with an increase of more than 3 orders of magnitude, and one where it is slightly disturbed deeper in the rock with an increase of 1 to 3 orders of magnitude (Armand et al. 2007). The extension of these two zones are detailed in figure 2 for one of the galleries and it can be related to the mixed and shear fractured zones of figure 1 .

\section{COUPLED LOCAL SECOND GRADIENT MODEL WITH HYDRAULIC PERMEABILITY VARIATION}

From the previous section, it clearly appears that modelling the modification of permeability inside the fractured zone is crucial. To do so, the fractures have firstly to be properly modelled with shear strain localisation.

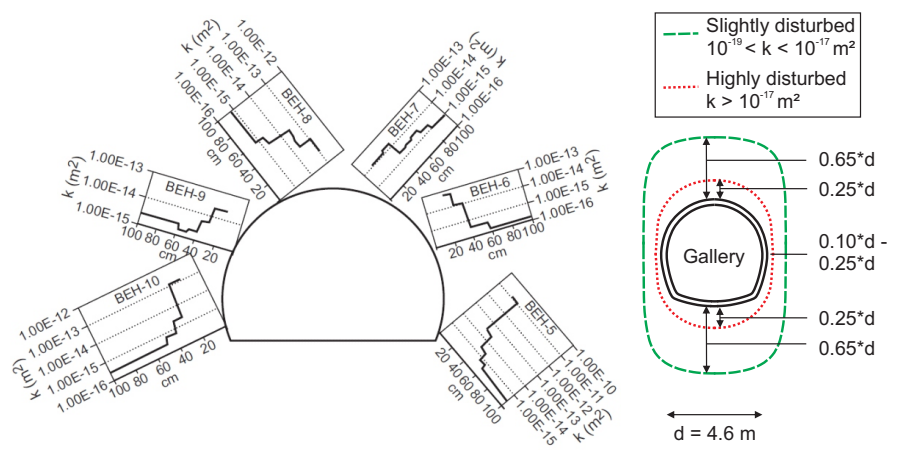

Figure 2: Hydraulic permeability increase around galleries in Opalinus clay (left) and in Collovo-Oxfordian claystone (right) (from Bossart et al. (2002) and Armand et al. (2007)).

Using classical finite element methods leads to a mesh-dependent problem thus a regularisation method is necessary to properly model the strain localisation (Collin et al. 2009). Different regularisation approaches exist and, among them, the coupled local second gradient model (Chambon et al. 1998) is chosen. It includes an enrichment of the kinematics with microstructure effects (Germain 1973). Collin et al. (2006) describe the theory for saturated multiphasic medium, we have extended it to unsaturated condition, taking into account the solid grain compressibility (see Pardoen et al. for details).

Once the strain localisation is properly modelled, the hydraulic properties modification and inhomogeneity inside the damaged zone can be considered. Different approaches exist to model the influence of the rock fracturing on permeability. From the wellknown relationship linking the saturated (intrinsic) hydraulic permeability to the porosity proposed by Kozeny-Carman to more complex models such as micro-macro approaches of permeability evolution (Levasseur et al. 2013).

\subsection{Balance equations}

For every kinematically admissible virtual displacement field $u_{i}^{*}$ and virtual pore water pressure field $p_{w}^{*}$, the mixture momentum balance equation and the water mass balance equation read in a weak form (Germain 1973, Collin et al. 2006):

$$
\begin{aligned}
& \int_{\Omega}\left(\sigma_{i j} \frac{\partial u_{i}^{*}}{\partial x_{j}}+\Sigma_{i j k} \frac{\partial \nu_{i j}^{*}}{\partial x_{k}}\right) d \Omega=\int_{\Gamma_{\sigma}}\left(\bar{t}_{i} u_{i}^{*}+\bar{T}_{i} D u_{i}^{*}\right) d \Gamma \\
& \int_{\Omega}\left(\dot{M}_{w} p_{w}^{*}-m_{w, i} \frac{\partial p_{w}^{*}}{\partial x_{i}}\right) d \Omega=\int_{\Omega} Q p_{w}^{*} d \Omega-\int_{\Gamma_{q}} \bar{q} p_{w}^{*} d \Gamma
\end{aligned}
$$

where $\sigma_{i j}$ is the total stress field, $\nu_{i j}^{*}=\frac{\partial u_{i}^{*}}{\partial x_{j}}$ is the virtual microkinematic gradient, $\Sigma_{i j k}$, which needs an additional constitutive law, is the double stress dual of the virtual micro second gradient, $\Omega$ denotes the current solid configuration (unit volume), $\bar{t}_{i}$ is the classical external traction force per unit area, $\bar{T}_{i}$ is an additional external double force per unit area, both applied on a part $\Gamma_{\sigma}$ of the boundary of $\Omega$ and $D u_{i}^{*}$ is $u_{i}^{*}$ normal derivative. Further, $\dot{M}_{w}$ is the time derivative of 
the fluid mass inside $\Omega, m_{w, i}$ is the fluid mass flow, $Q$ is a sink term and $\Gamma_{q}$ is the part of the boundary where the input water mass per unit area $\bar{q}$ is prescribed.

The total stress field is defined according to Bishop's postulate (Nuth and Laloui 2008):

$\sigma_{i j}=\sigma_{i j}^{\prime}-b S_{r, w} p_{w} \delta_{i j}$

where $\sigma_{i j}^{\prime}$ is the Bishop's effective stress field, $b$ is Biot's coefficient, $S_{r, w}$ is the water degree of saturation, $p_{w}$ is the pore water pressure, $\delta_{i j}$ is the Kronecker symbol.

\subsection{Solid and fluid phases behaviour}

Geomaterials are usually treated as porous materials composed of solid and fluid phases. Within the scope of poroelasticity (Coussy 2004), the solid density variation reads:

$\frac{\dot{\rho}_{s}}{\rho_{s}}=\frac{(b-n) S_{r, w} \dot{p}_{w}-\dot{\sigma}^{\prime}}{(1-n) K_{s}}$

where $\dot{\rho}_{s}$ is the solid grain density variation, $n$ is the material porosity, $K_{s}$ is the isotropic bulk modulus of the solid grains and $\dot{\sigma}^{\prime}$ is Bishop's mean effective stress variation. $K_{s}$ is calculated from the drained bulk modulus of the poroelastic material $K_{0}$ and Biot's coefficient which represents the compressibility of the solid grain skeleton:

$b=1-\frac{K_{0}}{K_{s}}$

Concerning the fluid phase, the water transfer in partially saturated porous media is modelled by Darcy's flow. The liquid advection and the fluid mass read:

$m_{w, i}=-\rho_{w} \frac{k_{i j} k_{r, w}}{\mu_{w}} \frac{\partial p_{w}}{\partial x_{j}}$

$M_{w}=\rho_{w} n S_{r, w} \Omega$

where $\rho_{w}$ is the water density, $k_{i j}$ is the intrinsic hydraulic permeability tensor, $k_{r, w}$ is the relative water permeability depending on the water degree of saturation, $\mu_{w}$ is the water dynamic viscosity. The retention curve and the water relative permeability curve are given by the van Genuchten's model (van Genuchten 1980). The gas pressure $p_{g}$ is assumed to be constant.

\subsection{Evolution of intrinsic hydraulic permeability}

Since strain is important in the localisation bands, an evolution of the permeability with a deformation parameter can be chosen. Using a variation with the porosity will highlight volumetric deformation effect. An exponential evolution is first considered if $n>n_{0}$ similarly to Chavant and Fernandez (2005):

$\frac{k_{i j}}{k_{i j, 0}}=1+\alpha\left(n-n_{0}\right)^{\beta}$

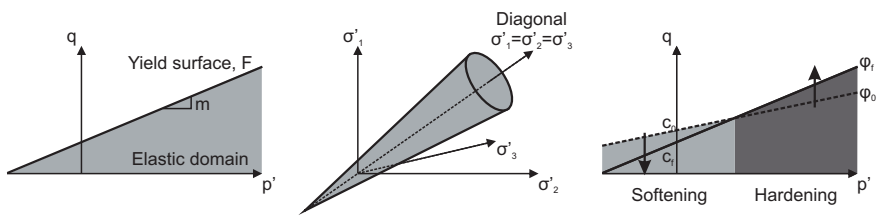

Figure 3: Drucker-Prager model : deviatoric stress versus mean effective stress plane (left), deviatoric space (center), hardening/softening (right).

where $k_{i j, 0}$ is the initial intrinsic water permeability, $n_{0}$ is the initial porosity, $\alpha$ and $\beta$ are two parameters. To highlight shear deformation effect, a variation with the total equivalent strain $\epsilon_{e q}$ is also considered:

$\epsilon_{e q}=\sqrt{\frac{3}{2} \hat{\epsilon}_{i j} \hat{\epsilon}_{i j}} \quad \hat{\epsilon}_{i j}=\epsilon_{i j}-\frac{\epsilon_{i i}}{3} \delta_{i j}$

where $\hat{\epsilon}_{i j}$ is the deviatoric strain tensor. Then, a similar exponential evolution can be chosen if $\epsilon_{e q}>\epsilon_{e q}^{t h r}$ :

$\frac{k_{i j}}{k_{i j, 0}}=1+\alpha\left(\epsilon_{e q}-\epsilon_{e q}^{t h r}\right)^{\beta}$

where $\epsilon_{e q}^{t h r}$ is a threshold value below which the intrinsic permeability variation is not considered. This type of evolution suit for slightly dilatant material such as the studied claystone.

\section{CONSTITUTIVE MODELS}

\subsection{First gradient mechanical law}

The constitutive mechanical law used for the clayey rock is a non-associated elastoplastic internal friction model with linear elasticity and a Drucker-Prager yield surface as detailed in Fig. 3:

$F \equiv I I_{\hat{\sigma}}-m\left(I_{\sigma}+\frac{3 c}{\tan \phi_{c}}\right)=0$

where $I_{\sigma}$ is the first stress invariant, $I I_{\hat{\sigma}}$ is the second deviatoric stress invariant, $\phi_{c}$ is the compression friction angle, $c$ is the cohesion and $m$ is a function of friction angle. The model allows friction angle and/or cohesion isotropic hardening and/or softening as a function of the equivalent plastic strain $\epsilon_{e q}^{p}$ (figure 3):

$$
\frac{\phi_{c}-\phi_{c 0}}{\phi_{c f}-\phi_{c 0}}=\frac{\epsilon_{e q}^{p}}{B_{\phi}+\epsilon_{e q}^{p}} \quad \frac{c-c_{0}}{c_{f}-c_{0}}=\frac{\epsilon_{e q}^{p}}{B_{c}+\epsilon_{e q}^{p}}
$$

where $\phi_{c 0}$ and $\phi_{c f}$ are the initial and final compression friction angles, $c_{0}$ and $c_{f}$ are the initial and final cohesions, coefficients $B_{\phi}$ and $B_{c}$ are the values of the equivalent plastic strain for which half of the hardening/softening is achieved.

\subsection{Second gradient mechanical law}

The second gradient law gives the double stress as a function of the micro second gradient. It is an isotropic linear elastic law depending on one elastic parameter $D$ and the shear band width is proportional to this parameter (Chambon et al. 1998). The double stress has no link with the pore water pressure. 
Table 1: Mechanical and hydraulic parameters for the Callovo-Oxfordian claystone.

\begin{tabular}{|c|c|c|c|c|c|c|c|}
\hline \multicolumn{4}{|c|}{ Mechanical parameters } & \multicolumn{4}{|c|}{ Hydraulic parameters } \\
\hline Symbol & Name & Value & Unit & Symbol & Name & Value & Unit \\
\hline$E$ & Young's modulus & 4000 & $M P a$ & $k_{11}$ & Horizontal intrinsic water permeability & $4 \times 10^{-20}$ & $m^{2}$ \\
\hline$\nu$ & Poisson's ratio & 0.3 & - & $k_{22}$ & Vertical intrinsic water permeability & $1.33 \times 10^{-20}$ & $m^{2}$ \\
\hline$b$ & Biot's coefficient & 0.6 & - & $n$ & Porosity & 0.18 & - \\
\hline$\rho$ & Specific mass & 2300 & $\mathrm{~kg} / \mathrm{m}^{3}$ & $M$ & van Genuchten coefficient & 0.33 & - \\
\hline$\psi$ & Dilatancy angle & 0.5 & $\circ$ & $N$ & van Genuchten coefficient & 1.49 & - \\
\hline$\phi_{c 0}$ & Initial friction angle & 10 & $\circ$ & $P_{r}$ & van Genuchten air entry pressure & 15 & $M P a$ \\
\hline$\phi_{c f}$ & Final friction angle & 20 & $\circ$ & $S_{\max }$ & Maximal degree of saturation & 1 & - \\
\hline$B_{\phi}$ & Hardening coefficient & 0.002 & - & $S_{\text {res }}$ & Residual degree of saturation & 0.01 & - \\
\hline$c_{0}$ & Initial cohesion & 3 & $M P a$ & $\mu_{w}$ & Water dynamic viscosity & 0.001 & Pas \\
\hline$c_{f}$ & Final cohesion & 0.3 & $M P a$ & $\alpha$ & Permeability variation parameter & $2 \times 10^{8}$ or 12 & - \\
\hline$B_{c}$ & Softening coefficient & 0.003 & - & $\beta$ & Permeability variation parameter & 3 & - \\
\hline$D$ & $2^{d}$ gradient parameter & 5000 & $N$ & $\epsilon_{e q}^{t h r}$ & Permeability variation threshold & 0.01 & - \\
\hline
\end{tabular}
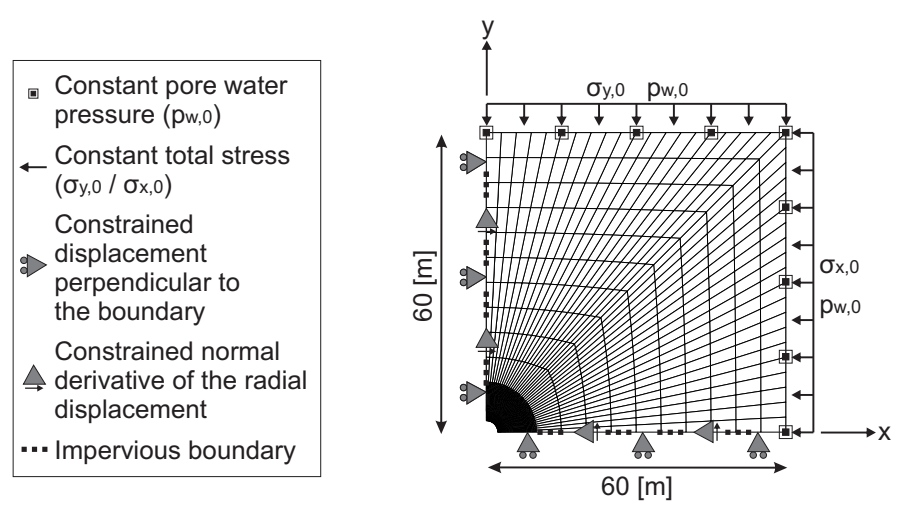

Figure 4: Schematic representation of the model used for the modelling of a gallery excavation.

\subsection{Mechanical and hydraulic parameters}

The Callovo-Oxfordian claystone parameters are detailed in Table 1 . They mainly come from laboratory testing and data fitting (Charlier et al. 2013).

\section{NUMERICAL MODELLING AND RESULTS}

\subsection{Gallery excavation modelling}

A hydro-mechanical modelling of a gallery excavation is performed in two-dimensional plane strain state. It takes into account the hydraulic permeability anisotropy (table 1) and the initial anisotropic stress state corresponding to a gallery of the Andra URL (Wileveau et al. 2007): $p_{w, 0}=4.5[M P a], \sigma_{h, 0}=$ $\sigma_{v, 0}=12[\mathrm{MPa}]$ and $\sigma_{H, 0}=1.3 \sigma_{v, 0}=15.6[\mathrm{MPa}]$ where $p_{w, 0}$ is the initial pore water pressure, $\sigma_{v, 0}$ is the vertical principal total stress, $\sigma_{h, 0}$ and $\sigma_{H, 0}$ are the minor and major horizontal principal total stresses. The gallery has a radius of 2.3 meters, it is oriented in the direction of the minor horizontal principal stress and gravity is not taken into account in the model.

The mesh and the boundary conditions are detailed in figure 4. Only one quarter of the gallery is discretised by assuming symmetry along the $\mathrm{x}$ - and $\mathrm{y}$-axes. The initial stresses and pore water pressure are imposed at the mesh limits, the water flow and the normal displacements are null along the symmetry axes. A second kinematic boundary condition is required to establish the symmetry due to the existence of gradient terms in the equilibrium equations (Zervos et al. 2001). The normal derivative of the tangential (radial) displacement has to cancel on the symmetry axes:

$$
x \text {-axis }: \frac{\partial u_{x}}{\partial y}=0 \quad y \text {-axis }: \frac{\partial u_{y}}{\partial x}=0
$$

The gallery excavation is executed in five days during which the total stresses and the pore water pressure at the gallery wall decrease from their initial values to the atmospheric pressure of $100[k P a]$. Then the calculation is extended to a thousand days under constant stress to highlight possible transient effects. The gallery ventilation and the permeability evolution are considered in the section 5.3 and 5.4 respectively.

\subsection{Damaged zone}

The numerical results in figure 5 present the evolution of shear strain localisation bands during and after the drilling. The results are the deviatoric strain increment, the total deviatoric strain $\epsilon_{e q}$ and the plastic zone. The modelling exhibits a chevron fracture pattern around the gallery corresponding to in situ observations. The fractures appear during the excavation and are concentrated above the gallery because of the material anisotropic stress state. The extension of the damaged zone is 0.1 gallery diameter in the horizontal direction and 1 gallery diameter in the vertical direction which corresponds fairly well to the in situ experimental measurements of shear fractures (figure 1).

\subsection{Gallery ventilation}

At gallery wall, it is assumed that the liquid water is in equilibrium with the water vapour (Kelvin's law):

$R H=\exp \left(\frac{-p_{c} M_{v}}{R T \rho_{w}}\right)$

where $R H$ is the air relative humidity, $M_{v}$ is the molar mass of water vapour $M_{v}=0.018[\mathrm{~kg} / \mathrm{mol}], R$ is the gas constant $R=8.314[\mathrm{~J} / \mathrm{molK}], T$ is the absolute temperature $T=298.15[K]\left(25\left[{ }^{\circ} \mathrm{C}\right]\right), \rho_{w}$ is the 


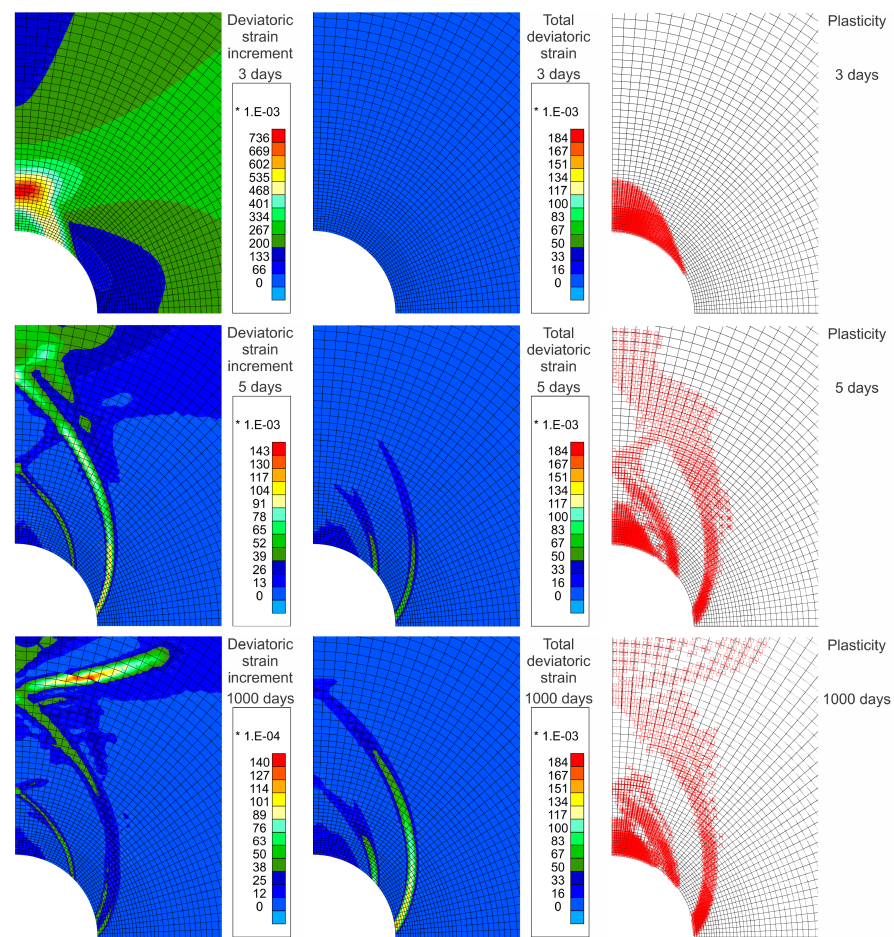

Figure 5: Evolution of the strain localisation during and after gallery excavation.
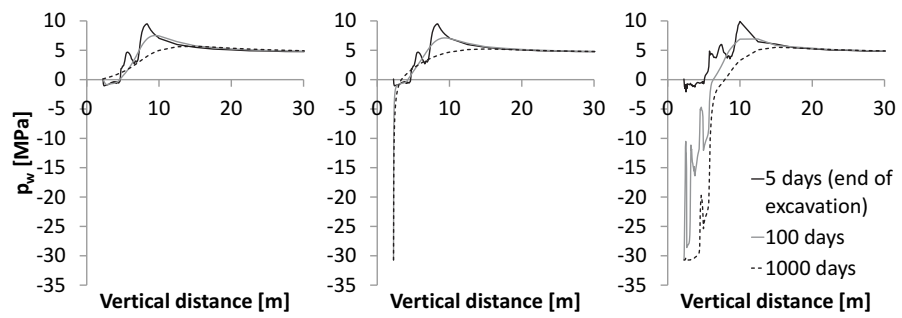

Figure 6: Pore water pressure evolution along the y-axis : no intrinsic permeability variation and no ventilation (left), no intrinsic permeability variation with ventilation (center), intrinsic permeability variation with $\epsilon_{e q}$ and ventilation (right).

liquid water density $\rho_{w}=1000\left[\mathrm{~kg} / \mathrm{m}^{3}\right]$, and $p_{c}$ is the capillary pressure $p_{c}=p_{g}-p_{w}$. Previously, the ventilation was not modelled ( $R H=100[\%])$, nevertheless ventilation is usually realised in galleries and can be modelled to observe its effects on the rock material. To do so, an air with $R H=80[\%]$ is chosen and applied on the gallery wall after the end of excavation.

The evolution of pore water pressure along the $y$ axis is detailed in figure 6 . The influence of the strain localisation bands is visible mostly during the excavation due to the strain increment inside the bands (band activity) and the hydro-mechanical coupling. When ventilation is computed, the suction induces the desaturation of the rock close the gallery wall. Results displayed in figure 7 show that the suction strongly influences the plasticity. Following Bishop's stress definition, higher the suction, higher the effective stress, meaning that the material becomes elastic again. This inhibits the shear strain localisation.

The evolution of the gallery convergence is detailed in the figure 8 where the matching with experimental results from the same gallery of the Andra URL is presented (Armand et al. 2013). One can observe that the inhibition of the shear strain localisation by

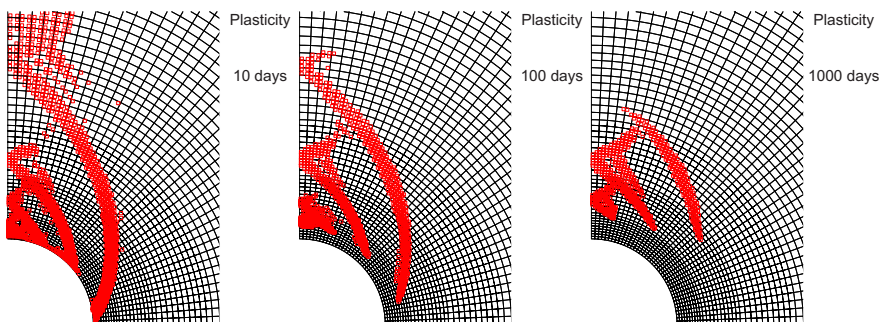

Figure 7: Evolution of the plastic zone after gallery excavation with air ventilation.
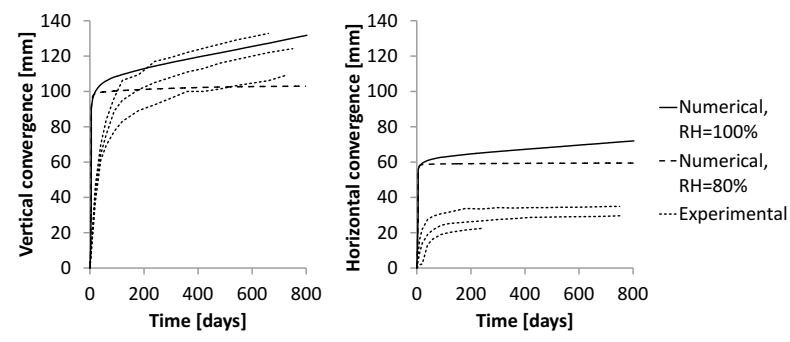

Figure 8: Evolution of the vertical (left) and horizontal (right) convergence during and after gallery excavation with comparison to experimental results.

the ventilation restricts the deformation. The convergence is anisotropic due to the shear strain localisation bands above the gallery which imply larger displacements. Besides, the simulation without ventilation gives a good prediction of the convergence in the vertical direction but overestimates it in the horizontal direction. In that direction, the proximity of the shear band localisation induces excessive deformations.

\subsection{Permeability variation}

The evolution of intrinsic hydraulic permeability is added to the computation from the beginning of the drilling. Firstly, we compute the permeability evolution depending on the porosity of equation $8(\alpha=$ $2 \times 10^{12}, \beta=3$ ). The results in the figure 9 illustrate the horizontal permeability variation at the end of the excavation. One can observes that it increases of several orders of magnitude around the gallery. Even if the increase is higher in the localisation bands, it remains quite diffuse, especially in the horizontal direction. Nevertheless, we obtain a fairly good matching with the in situ experimental measurements of permeability (figure 2).

Secondly, we compute the permeability evolution depending on the total equivalent strain of equation 10 $\left(\alpha=2 \times 10^{8}, \beta=3, \epsilon_{e q}^{t h r}=0.01\right)$. In this case, the per-
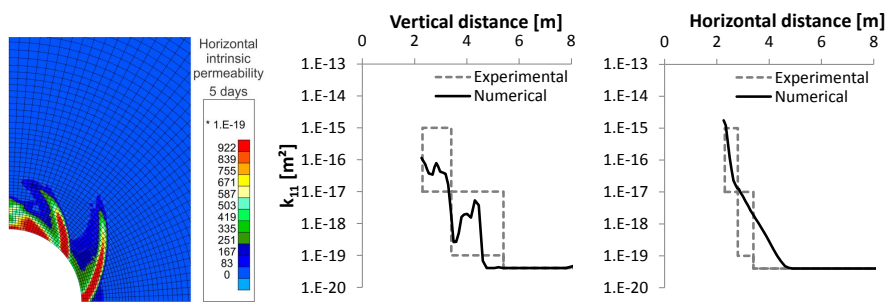

Figure 9: Variation of the horizontal intrinsic water permeability due to the porosity at the end of the excavation : 2D mapping (left), evolution along the $y$-axis (center) and the $\mathrm{x}$-axis (right). 

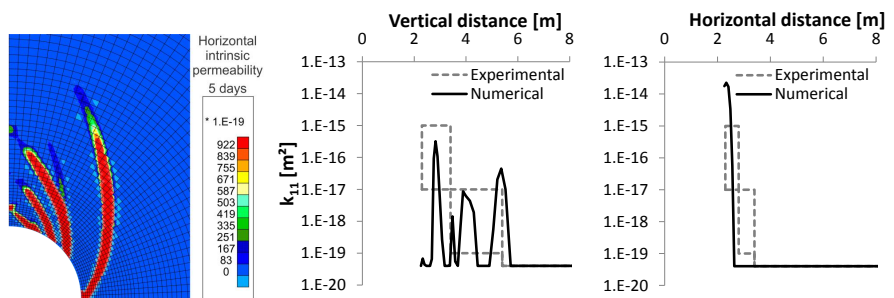

Figure 10: Variation of the horizontal intrinsic water permeability due to the total equivalent strain at the end of the excavation : 2D mapping (left), evolution along the y-axis (center) and the $\mathrm{x}$-axis (right).
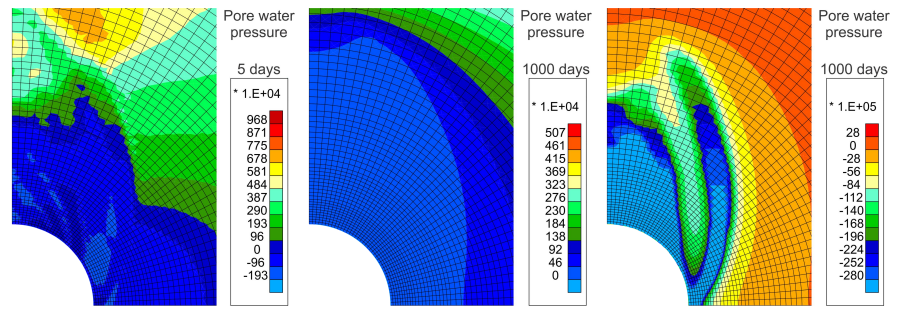

Figure 11: Pore water pressure distribution around the gallery : end of the excavation (left), 1000 days after the excavation without ventilation (center) and with ventialation (right).

meability evolution is related to the shear deformation which is concentrated in the localisation bands. The results in the figure 10 indicate that, at the end of excavation, the permeability has strongly increased in the localisation bands representing the fractures. This corresponds to experimental observations and measurements. The influence of air ventilation after the drilling is clearly highlighted in the figure 11. It drains and desaturates the damaged zone especially in the localisation bands.

The evolution of pore water pressure along the yaxis is detailed in figure 6 (right). The depth to which the desaturation extends increases significantly when the permeability variation is considered. In this case, the influence of the bands is visible after the excavation due to the permeability variation.

\section{CONCLUSION}

The fracturing and permeability variation around a gallery has been modelled with strain localisation in shear band mode. To this end, the second gradient theory has been successfully extended to multiphasic porous media under unsaturated condition, taking into account the solid grain compressibility and permeability variation. Numerical results highlight that the EDZ around a gallery in claystone had been fairly well modelled. Within this zone, the modelling provides information about the evolution of the fracture structure and flow properties as observed in situ. The convergence is well reproduced, the influence of permeability variation and gallery ventilation have also been highlighted. Nevertheless, it would be interesting now to improve the modelling with a more accurate definition of the rock anisotropy and the influence of damage on hydro-mechanical properties.

\section{REFERENCES}

Armand, G., F. Leveau, C. Nussbaum, R. de La Vaissiere, A. Noiret, D. Jaeggi, P. Landrein, \& C. Righini (2013). Geometry and properties of the excavation induced fractures at the Meuse/Haute-Marne URL drifts. Rock Mech. Rock Eng. in press.

Armand, G., Y. Wileveau, \& J. Delay (2007). Analyse des perméabilités mesurées autour des ouvrages du LSMHM au niveau $-490 \mathrm{~m}$ pour déterminer des lois empiriques utilisables dans des calculs hydromécaniques couplés en milieu continu. Technical Report D.NT.ALS.07.0453, Andra.

Bossart, P., P. Meier, A. Moeri, T. Trick, \& J. Mayor (2002). Geological and hydraulic characterisation of the excavation disturbed zone in the Opalinus Clay of the Mont Terri Rock Laboratory. Eng. Geol. 66, 19-38.

Chambon, R., D. Caillerie, \& N. El Hassan (1998). Onedimensional localisation studied with a second grade model. Eur. J. Mech. A-Solid 17, 637-656.

Charlier, R., F. Collin, B. Pardoen, J. Talandier, J. Radu, \& P. Gerard (2013). An unsaturated hydro-mechanical modelling of two in-situ experiments in Callovo-Oxfordian argillite. Eng. Geol..

Chavant, C. \& R. Fernandez (2005, March). Evaluating the reliability of hydro-mechanical simulation : A benchmark of numerical techniques carried out by Research Group of MoMas. In Andra (Ed.), 2nd International Meeting Clays in Natural and Engineering Barriers for Radioactive Waste Confinement, Tours, France, pp. 14-18.

Collin, F., R. Chambon, \& R. Charlier (2006). A finite element method for poro mechanical modelling of geotechnical problems using local second gradient models. Int. J. Numer. Meth. Eng. 65, 1749-1772.

Collin, F., S. Levasseur, \& R. Chambon (2009). Numerical post failure methods in multiphysical problems. Eur. J. Environ. Civ. Eng. 13, 983-1004.

Coussy, O. (2004). Poromechanics. New York: John Wiley.

Cruchaudet, M., A. Noiret, J. Talandier, B. Gatmiri, \& G. Armand (2010). OHZ en GED: EDZ initiale et évolution. Technical Report D.RP.AMFS.11.0016, Andra.

Desrues, J. (2005). Hydro-mechanical coupling and strain localization in saturated porous media. Rev. Eur. Génie Civ. 9, 619-634.

Germain, P. (1973). The method of virtual power in continuum mechanics. Part 2 Microstructure. SIAM J. Appl. Math. 25, 556-575.

Levasseur, S., F. Collin, R. Charlier, \& D. Kondo (2013). A micro-macro approach of permeability evolution in rocks excavation damaged zones. Comput. Geotech. 49, 245-252.

Nuth, M. \& L. Laloui (2008). Effective stress concept in unsaturated soils: Clarification and validation of a unified framework. Int. J. Numer. Anal. Met. 32, 771-801.

Pardoen, B., S. Levasseur, \& F. Collin. Using local second gradient model and shear strain localisation to model the excavation damaged zone in unsaturated claystone. In preparation.

Tsang, C., F. Bernier, \& C. Davies (2005). Geohydromechanical processes in the Excavation Damaged Zone in crystalline rock, rock salt, and indurated and plastic clays - in the context of radioactive waste disposal. Int. J. Rock Mech. Min. 42, $109-125$.

van Genuchten, M. (1980). A closed-form equation for predicting the hydraulic conductivity of unsaturated soils. Soil Sci. Soc. Am. J. 44, 892-898.

Wileveau, Y., F. Cornet, J. Desroches, \& P. Blumling (2007). Complete in situ stress determination in an argillite sedimentary formation. Phys. Chem. Earth 32, 866-878.

Zervos, A., P. Papanastasiou, \& I. Vardoulakis (2001). Modelling of localisation and scale effect in thick-walled cylinders with gradient elastoplasticity. Int. J. Solids Struct. 38, 5081-5095. 